\title{
Introducing IT: Lessons from Case Studies of Email
}

Link to publication record in Manchester Research Explorer

\section{Citation for published version (APA):}

Jakobs, K., Procter, R., \& Williams, R. (1997). Introducing IT: Lessons from Case Studies of Email. In Proceedings of Factory 2000: The Technology Exploitation Process (pp. 145-152). IEE.

\section{Published in:}

Proceedings of Factory 2000: The Technology Exploitation Process

\section{Citing this paper}

Please note that where the full-text provided on Manchester Research Explorer is the Author Accepted Manuscript or Proof version this may differ from the final Published version. If citing, it is advised that you check and use the publisher's definitive version.

\section{General rights}

Copyright and moral rights for the publications made accessible in the Research Explorer are retained by the authors and/or other copyright owners and it is a condition of accessing publications that users recognise and abide by the legal requirements associated with these rights.

\section{Takedown policy}

If you believe that this document breaches copyright please refer to the University of Manchester's Takedown Procedures [http://man.ac.uk/04Y6Bo] or contact uml.scholarlycommunications@manchester.ac.uk providing relevant details, so we can investigate your claim.

\section{open Access}




\title{
INTRODUCING IT: LESSONS FROM CASE STUDIES OF E-MAIL
}

\author{
Kai Jakobs ${ }^{1}$, Rob Procter, Robin Williams
}

University of Edinburgh, UK

\begin{abstract}
Adoption and implementation of electronic messaging systems in large international organisations creates a number of non-technical problems. Based on results of case studies of organisational implementations of e-mail services these issues are identified and discussed, and the strategies employed to overcome them analysed. Subsequently, end-user issues related to messaging services are discussed. We examine the different degrees of user training and support offered, and the mechanisms in place allowing end-users to contribute to subsequent service developments and enhancements. We conclude with recommendations for tackling some of the problems observed.
\end{abstract}

\section{INTRODUCTION}

One of the central dilemmas in the organisational implementation of Information Technology (IT) today concerns the relationship between the central and the local. On the one hand, the vision of the strategic application of IT advanced, for example, by proponents of Business Process Re-design (Hammer and Champny, 1993), implies a centrally planned, top-down design and implementation of systems coupled to a radical transformation of organisational practice. On the other hand, research into IT implementations has revealed the importance of bottom-up strategies allied to local individual and collective learning processes in which technical potential is explored and fitted to the specific current and emerging requirements of groups of organisational end-users (Friedman, 1989; Fleck, 1994). The latter points to the contingency and heterogeneity of organisational information systems, viewed as complex configurations of diverse technologies and working practices. However, such a heterogeneous approach to IT systems remains problematic in relation to distributed IT systems, which exhibit strong network externalities, i.e. where the value for each user of being on the network increases with every new player joining the network. For example, if different local systems are incompatible, this will limit the benefits available from using the system.

For distributed IT systems such as electronic messaging services, two kinds of barriers to successful implementation may be particularly important. The one most commonly recognised is at the technical level of interoperability, where differences between various proprietary solutions or different generations of technology may mean that systems cannot interoperate or that some functions cannot be shared. However, another, potentially more significant barrier in terms of the cost and effort needed to overcome it arises from the commitment of end-users to their own locally-chosen systems -- which may represent a substantial investment made by large numbers of people to learning how to use a system and to apply its functionality to their working activities. This may result, for example, in a reluctance on the part of some end-users to comply with the imposition of organisation-wide, standardised services.

We explore these and other, related issues through of a number of case studies of the implementation -- i.e. adoption and development -- of e-mail services in large, international organisations in a variety of different business sectors including finance, chemistry, aviation, and oil.

\section{BACKGROUND AND MOTIVATION}

The work reported here is part of a wider project examining those factors contributing to useful and usable electronic messaging services. Previous work has focused on the processes by which messaging standards are defined. The growing requirement for interoperability has established the need for standardised communications services. More recently, messaging standards have targeted higher level services, and the results have direct consequences for usability. Thus, the achievement of the desired high levels of usability makes it increasingly important to understand how standardisation processes work and, in particular, if and where they fail to address users' requirements, and why (Cargill, 1989; Hawkins et al., 1995; Jakobs et al., 1996).

E-mail was selected for in-depth study because it is by far the most popular network application, being utilised by an ever increasing number of users with diverse backgrounds and expectations. E-mail has by now made its way into the offices of virtually all large international organisations. Recent studies (e.g. Bagshaw and Lockwood, 1994) suggest that once it has been introduced at an organisation-wide level -- and thus network externality benefits fully exploited -- e-mail yields considerable advantages over traditional communication media such as letter, telex, fax, and phone. This holds not only for internal communication, 
but all the more if external business partners are accessible this way too. Major benefits identified include savings of time and money and process simplification, as well as enhanced reachability and cooperation.

Despite these significant advantages, however, companies implementing e-mail services have found themselves facing a number of problems. There are many factors which may impact upon the adoption of email services and their subsequent take up and usage. Those of a more technical nature, such as functionality, reachability etc. are well-documented (Race Industrial Consortium, 1995). This paper focuses upon organisational factors and, in particular, the strategies employed (if any) in the adoption and development of email services. We report on how organisations have responded to the problems of interoperability and the dilemma of bottom-up versus top-down implementation strategies, and the degree of attention paid to end-user issues such as training, the provision of adequate support facilities, and establishment of effective channels for user feedback as development proceeded.

\section{METHODOLOGY}

The study focused on large, globally operating enterprises. It was assumed that such companies would be more likely to have gained considerable experience with e-mail systems, to have employed real introduction strategies, and to have implemented adequate mechanisms to cope with user comments. Membership in user organisations -- e.g. the European Electronic Messaging Association (EEMA) -- was another selection criterion, as it was felt that such membership was indicative of a higher than average degree of interest in the subject. Companies studied were from very different sectors, including but not limited to finance, information brokering, transport, and petro-chemicals. Finally, the study was geographically limited to UKbased companies and branches.

Fifteen senior members of IT departments who also represented their respective companies within EEMA were interviewed. Typically, interviews lasted between one and three hours, and focused on:

- general experiences of electronic messaging services,

- introduction strategies used (if any),

- approaches how to address user-related issues,

- technical shortcomings of the systems used, if any, and

- how such shortcomings were overcome.

In addition to these face-to-face interviews, some company representatives were interviewed through questionnaires. In both cases, a common set of twentytwo open-ended questions was employed.

\section{E-MAIL IMPLEMENTATION STRATEGIES}

In this section we will describe and categorise the different strategies for the adoption and development of company-wide e-mail services within our case study organisations, and discuss their respective pros and cons. In doing so, it is necessary to link these strategies to the respective history of messaging services, that is to the situation that had emerged within each organisation before a central, corporate, top-down strategy was imposed. As will become clear, in the vast majority of case study organisations such a strategy was implemented only at a rather late stage. Only rarely was there evidence of a top-down strategy being followed throughout adoption and development (Jakobs and Fichtner, 1995).

\section{Top-Down Strategies}

The advantage of pursuing a top-down strategy right from the beginning of e-mail service implementation is that compatibility issues are more easily resolved and a solution providing homogeneous services throughout the whole organisation will be much more costeffective. Also, the backing of senior management removes many obstacles.

\section{"The decision to use electronic messaging was backed by the board of directors. Accordingly, the introduction brought at least very few organisational problems."}

However, one of the major drawbacks of pursuing a topdown strategy from the outset is that it removes the opportunity for individual and organisational learning, which may have serious consequences for the success of the project (Attewell, 1992). This was the experience of one of our case study organisations, where the introduction of e-mail was initially confounded by users' resistance to change. This resistance was itself directly linked to the fact that at that time the project began, email's benefits were not really understood.

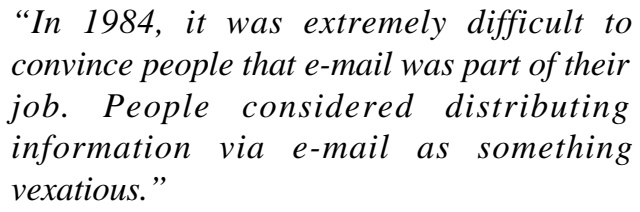

The organisations which followed a top-down strategy from the outset were either the smaller ones, or relatively young organisations founded within the last twenty years.

\footnotetext{
"The company was lucky in that one of its founders was quite keen on IT, so funding has not really been a problem. In the early days, decisions related to information
} 
technology in general, and to e-mail in particular, were very much taken by this person."

Even in these cases, it was noted that following a topdown strategy only eased the introduction of the first system; subsequent moves, e.g. from mainframe-based towards LAN-based systems, still caused considerable problems.

\section{Hybrid Strategies}

Overall, the results of the study suggests that large, international enterprises do not normally make topdown, strategic decisions about messaging services from the very beginning. This result may partly reflect the structure of the case study organisations, the majority of which are subdivided into a number of almost autonomous companies or branches, located around the globe. The result was that end-users typically took the lead in e-mail adoption. Whether deliberate or otherwise, the benefit was the opportunity thus provided for the individual and organisational learning so often vital to the subsequent successful organisation-wide implementation of IT systems.

Typically, we found that IT-related decisions were made at departmental or site level. The result of this was that the IT environments in the case study organisations, particularly (but not only) messaging systems, were generally very heterogeneous. In general, this situation was aggravated by the existence of different generations of equipment, including mainframes, minis and workstations as well as an ever increasing number of PCs.

The consequence of a pattern of local, end-user led adoption on the one hand and the obstacles created by heterogeneous systems to interoperability on the other was the emergence of two distinct hybrid strategies which combined elements of bottom-up and top-down strategies, but in rather different ways. The first hybrid strategy we found holds for about two thirds of the organisations within the case study. In it, bottom-up adoption and top-down development strategies are pursued at different phases within the overall implementation process.

The Initial Phase. In classical bottom-up fashion, a group of employees obtained a messaging tool, either to fulfil a specific work requirement, or bundled in with other software.

\footnotetext{
"The first e-mail system was installed as part of a major IT project, when it was merely considered a tool enabling cooperation between project teams in 17 European countries. Its introduction was part of the
}

\section{project roll-out, and based on a management decision."}

\section{"Use of e-mail emerged from the use of $V A X$-mail, which came for free with the operating system."}

The new service soon became popular. Slowly, mainly by word of mouth, information about benefits provided spread throughout the department.
"Word processors were bought, with e-mail being an integral part of this package, to be used by secretarial staff. Since then, electronic mail has made its way into other offices and departments."

The number of users increased steadily, though still within the department or site, rather than at the organisational level. However, at the same time very similar developments took place at many sites, resulting in an extremely heterogeneous environment (see fig. 1) -- the inevitable outcome of the bottom-up approach. The conditions potentially now existed to justify the pursuit of a top-down strategy to e-mail service development.

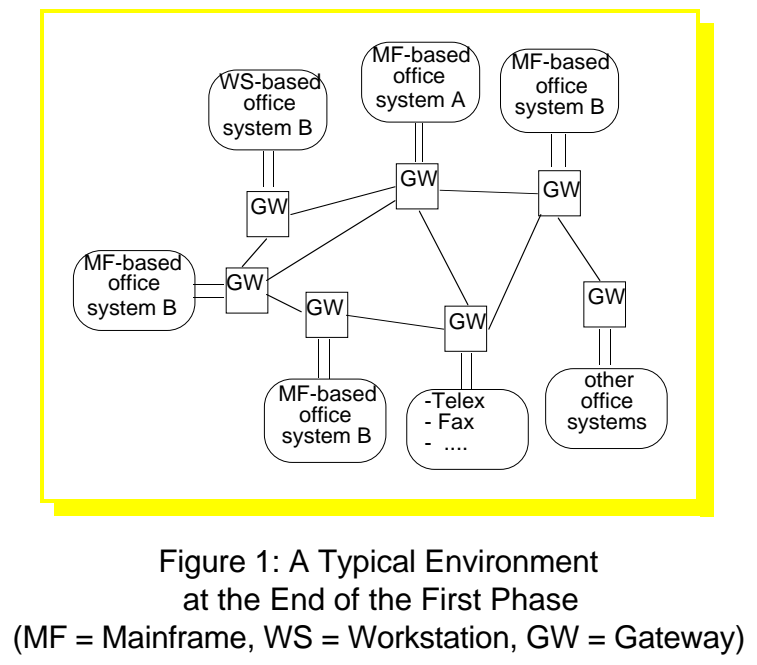

The Second Phase. Users now recognised the need for integration as they experience the problems of the incompatibilities between the patchwork of systems adopted at different sites. In some cases, there were more than ten different mail systems. The degradation of organisation-wide communication quality was severe and often costly and frustrating for users.

The case for following a central, top-down development strategy as a solution to these problems was now very strong. Unfortunately, its acceptance depended upon senior management being convinced that the major expenditures related to purchasing, installing and maintaining a (more or less) homogeneous e-mail service were justified by the benefits. A critical mass of 
e-mail users had to be reached -- and individual and organisational learning had to take place -- before the implications of factors such as network externalities could be fully appreciated and the costs of a top-down strategy thereby justified.

Attempts to institute a top-down development strategy began: a central entity took over and tried to integrate the different services with management backing.

\section{"Originally it was an effort led by techies,} now it has much management support."

Fig. 2 sketches a messaging environment which could typically be found some time after implementation of a top-down strategy.

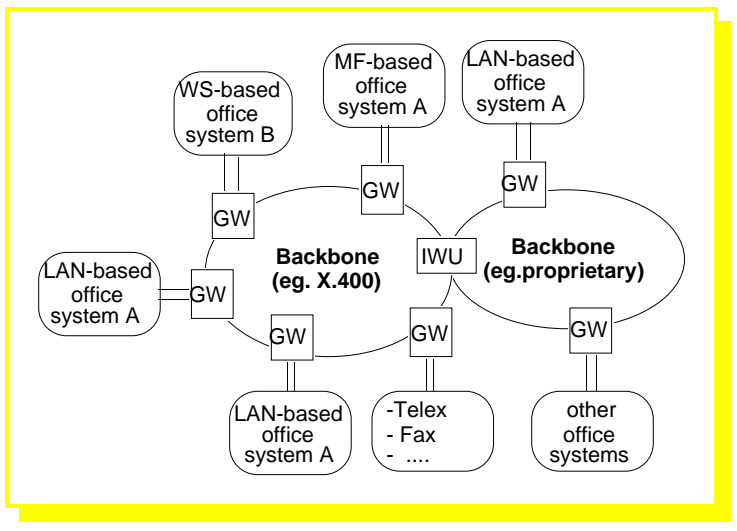

Figure 2: A Typical Environment

During the Second Phase

IWU = Interworking Unit

Also during this phase most organisations started looking at more flexible and feature-rich systems, which were typically to be found on PCs or UNIX machines.

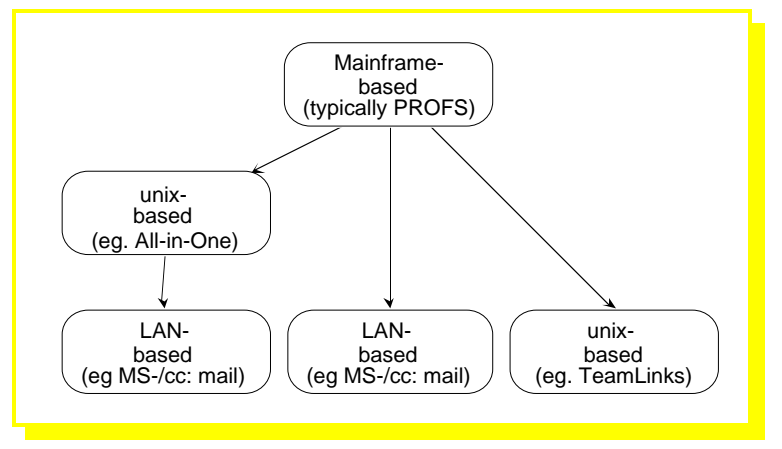

Figure 3: Typical Evolution of Electronic Mail Service Platforms

Another development supporting this migration was the then popular move away from (mainframe) IBM to smaller (UNIX-based) systems. In contrast to the initial service introduction, this move was always part of a top-down development strategy. This a general trend towards a higher degree of service distribution, this has been achieved via different evolution paths (see Figure 3).

The Third Phase. This phase, which many of the case study organisations are currently pursuing, is a continuation of the top-down development strategy, and is characterised by the introduction of a uniform local email environment (e.g. MS-Mail or cc:Mail), interconnected through a messaging backbone (typically an X.400-based system or the Internet), which also offers access to the respective other e-mail world (i.e. the Internet or X.400). Completion of this step means that a homogeneous service will be available for most, if not all, users, and that the number of different gateways will be minimised (cf. fig. 4).

\section{"Until we've got to the stage we've got an entire user population on one e-mail system we're going to have a degree of user annoyance."}

Whilst this may be an unrealistic goal for the time being, there is no doubt that this statement is true. As has been noted earlier, interconnection of different mail systems via gateways always leads to a loss of functionality, which in turn will frustrate affected users.

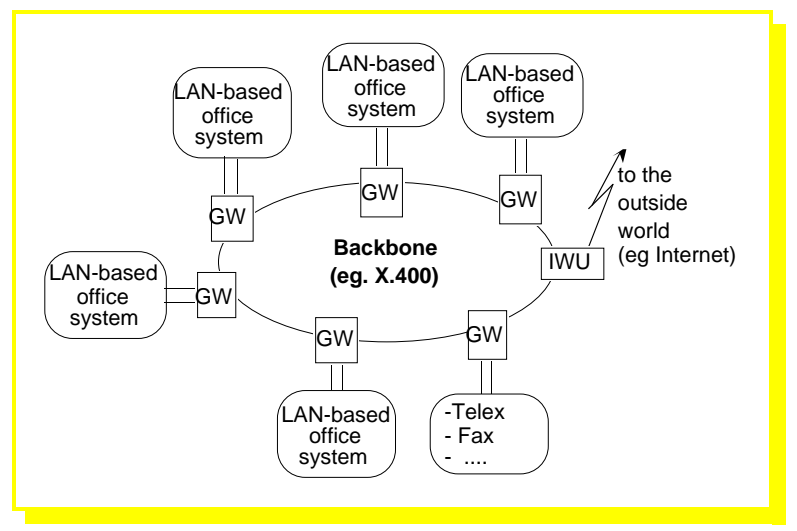

Figure 4: The Envisaged Final Outcome of the Process

Some of the case study organisations have gone to great lengths to push forward LAN-based systems, a move typically also resulting in problems, including:

\section{- Convincing management}

The establishment of the first e-mail systems was achieved fairly painlessly and without major financial expenditure. However, convincing top management that a move from an apparently working service towards something new was typically quite difficult.

\section{- Service uptake}

Despite their various advantages, LAN-based systems incurred a considerable extra overhead compared to centralised mainframes. 


\section{- Convincing users}

Once staff got accustomed to using to a certain service, organisations found it hard to persuade them to use something else instead. This was even more the case if the new service was still in its infancy, and likely to cause problems for some time.

\section{- System interconnection}

There was almost universal agreement that a single e-mail service was the best solution for organisational messaging needs. However, this proved to be very difficult to achieve in practice. Consequently, most organisations have opted to establish an interconnecting (and integrating) email backbone instead.

In contrast to the first hybrid strategy, where bottom-up and top-down strategies are pursued sequentially and contingently, the second hybrid strategy we found integrates the two in a systematic and pre-planned way: bottom-up adoption is steered and controlled through a parallel, overarching, top-down implementation strategy (Jakobs and Lenßen, 1994).

Use of the second hybrid strategy was observed within a large French chemical group. Sales staff and a special communications group were the first to be involved in the project. A simple adoption strategy was followed: people known be interested in trying and testing new techniques were persuaded to use the new e-mail service. Those people then had something like a catalyst function within their respective departments, serving to promote the further introduction of the system. Messaging could be demonstrated as being an attractive service. It was always made very clear that messaging was not intended to be a replacement of other established communication media, but an additional service, and that messaging would be as easy to use, and at least as effective as other communication services. Stressing these facts was considered crucial, as gaining users' confidence has always been a vital part of the internal marketing strategy.

Eventually, management and other senior personnel learned about the benefits of e-mail, largely by word of mouth. Once these people were enthusiastic about messaging, it became an important tool in their departments within very short time. It turned out that people suddenly found they had various obligations that forced them to use e-mail. In fact, this was simply because colleagues or superiors were using the system. This development was supported by group meetings, where messaging benefits had been presented, with senior staff sharing their related experiences. Such private success stories and experiences, as well as concrete business cases, contributed significantly to the system's further uptake.
This hybrid approach is of particular interest because it represents an attempt to combine the advantages of a pure top-down implementation strategy -- i.e. its speed- with the advantages of a bottom-up adoption strategy- i.e. the opportunities for organisational learning -- but without the latter's disadvantages -- i.e. the problems of incompatibility.

\section{END-USER ISSUES}

This section discusses the steps taken by the case study organisations to satisfy the needs of their users, and to promote the take up and usage of the e-mail service. Of numerous influential factors (see e.g. Yaverbaum, 1988), the topics addressed include user training, support facilities, and provision of channels to forward complaints, suggestions, problems etc. The latter may be taken as a measure, in part, of users' scope for contributing to subsequent service developments.

\section{User Training And Support Facilities}

Attitudes varied with respect to user training. The range of comments included

\section{"Full user support on technical issues is provided on site, including user training" \\ "User support enjoys comparably low priority”.}

This is quite surprising, given the fact that the importance of user training has long been recognised, (see e.g. Nelson and Cheney, 1987).

The majority of the organisations considered (re)training of users as being of principal importance. In most cases, a substantial amount of time and money has gone into these issues, which include initial training courses for management and support staff; 'training the trainers' being a popular first step. Moreover, staff are employed by some of the organisations to serve in a training role, and to produce specific service documentation.

One company, which insists that staff follow an introductory training courses, considers e-mail as a major (positive) part of today's corporate culture, a view with which staff apparently concur. On the other hand, two companies said that user training is low on their respective priority lists. Although this number is certainly too small to draw any general conclusions, it is nevertheless interesting to note that one of these latter companies sees itself as being "still at an early stage of e-mail use" (after about eight years), with the other admitting that "despite their efforts e-mail is not widely used". 
As discussed earlier, the commitment of end-users to their own locally-chosen systems may represent an important barrier when services are integrated and standardised. Some of the case study organisations have realised that forcing users to move from one e-mail system to another is not a good policy. Rather, they have tried to 'persuade' their users to move in the desired direction, by offering, for example, migration tools and better support facilities for the new service, yet whilst retaining (for some interim period) interconnection to the old one.

Despite the different attitudes towards training, the case study organisations are unanimous in their belief that help-desks are crucial to success. In fact, every of them offers access to a help-desk facility to its users, either internally or through a third party.

\section{End-Users and Service Development}

The organisations show similarly diverse approaches towards compilation of -- and reaction to -- user reports, suggestions and complaints. Whereas some do have rather sophisticated mechanisms in place for automatic logging of such user input, and have formally established bodies to analyse and react upon these reports, others simply leave it to the help-desk staff. The quality and volume of user input itself seems to reflect the respective approaches: users who know that their comments will be considered seriously appear to be much more willing to actually submit them (Jakobs, 1994).

One of the organisations in the case study has attempted to place users at the centre of policy-making about email services, and is exploiting e-mail as a vehicle for requirements elicitation. A field request logging system is in place through which comments etc. can be sent to a central site where full-time staff are in charge of collating and analysing them. The results are then forwarded to the responsible service manager. A communication user group of about thirty people, drawn primarily from senior management, is responsible for long term service planning. It is within this group that compromises (where necessary) between local and organisation-wide requirements are determined. Recently, the company introduced MIME in response to user demand. Prior to a new product release, both a draft and a total requirements study are performed. So far, staff report that this approach has worked very well.

In contrast, a large proportion of the organisations stated that users have very little, if any, constructive requirements beyond the functionality they are offered. A correlation was apparent between the lack of user feedback and the absence of explicit support mechanisms for conveying and handling it.
Finally, an earlier report on user messaging behaviour within the same group of organisations observed that about four years after the introduction of e-mail, typically some $50 \%$ of their users were in a so-called 'bad traffic' zone, i.e. receiving or sending less than one message per day on average (Jakobs and Lenßen, 1994). Most of these 'bad' users commented to the effect that "it is not my fault that the traffic is that bad, there is nobody in the company who is willing to send me a message!". Three years later, half of these once 'bad' users had become 'normal' users, that is, they sent or received between 5 to 10 messages per day. This change was primarily due to better connectivity, and better integration of messaging services into the normal working environment.

Overall, we found that users within the case study organisations have generally responded positively to the introduction of e-mail services, but note that:

- e-mail services will lose their appeal if users do not receive 'enough' messages and

- it is important that progress continues to be made in terms of enhanced services.

\section{CONCLUDING REMARKS}

The dilemma between centralised, centralised, top-down and distributed, bottom-up strategies for system implementation is perhaps unavoidable in the attempts of very large, multi-divisional organisations to experiment with new and evolving technologies. Indeed, it lies at the heart of the continuing debate over the management of end-user computing (see e.g. Brancheau and Brown, 1993). Measures to limit experimentation with new technical alternatives to centralised functions would act as a barrier to innovation by reducing the scope for individual and organisational learning. This is one of the reasons why large bureaucracies in public administration and financial services were much slower than manufacturing organisations in adopting distributed computing (Adler and Williams, 1991). Management responses to end-user computing have been characterised variously as 'monopolist', 'laissez-faire' and 'managed free economy' (Gerrity and Rockart, 1986). The evidence of our case studies points to the apparent domination of laissez-faire strategies for e-mail service adoption which, as we have seen, leads to major problems once organisations are forced to grasp the nettle of interoperability and system incompatibilities.

Of the alternatives, a better strategy than the monopolist approach of suppressing locally-generated innovation, might be to develop policies that cater for it, and allow it to be fostered within more an overarching strategy. An example might be the second hybrid strategy revealed in our case studies. More specifically, given the 
importance of compatibility to services like e-mail, it might be useful to encourage local innovations on the condition that the need for migration strategies to eventual organisation standards is addressed. This might, for example, involve giving preference to systems built on open standards, including proprietary industry standards that have been opened out to complementary suppliers, and especially to 'architectural technologies' where some elements of a product remain constant, providing some guarantee of compatibility over several product generations (Morris and Ferguson, 1992).

Technical limits on interoperability constitute one potentially important barrier to such migration. Another barrier, which is arguably more substantial, is the commitment of end-users to their chosen systems and their investment in learning how to use them and adapt them to their working routines. The cumulative investment made by large numbers of organisation members is likely to be large relative to the costs of system acquisition -- as are the costs of transferring from the locally chosen system to the one adopted as the organisation standard. As our case studies show, users can be very reluctant to move from one system to another. Various persuasion tactics were in evidence in our case studies, but results were mixed.

User acceptance will be improved if the transfer to the new system is made relatively painless through the provision of useful migration tools (e.g. allowing users to retain their address directories they have developed; not needing to change existing e-mail addresses, etc.). A natural extension of this approach would be to provide the facility for users to retain the broad look and feel of the user interface (e.g. command language). Though such a proposal may seem difficult to achieve, the network externality benefits of standard user interfaces may themselves result in the widespread adoption of certain industrial standards in this area (Williams, 1993). Ultimately such external standards, for example for Electronic Data Interchange, may provide a template for internal integration and standardisation.

\section{REFERENCES}

Adler, M. and Williams, R. (eds.), 1991, The Social Implications of the DSS Operational Strategy, Social Policy Series No.4, The University of Edinburgh.

Attewell, P., 1992, Technology diffusion and organisational learning: The case of business computing, Organizational Science 3 (1), pp. 1-19.

Bagshaw, E. and Lockwood, R., 1994, Desktop Messaging -- Strategies for the Corporate Market, Ovum Report, ISBN 0903969920.
Brancheau, J. and Brown, C., 1993, Management of End-User Computing, ACM Computing Surveys, Vol. 25 (4), pp. 437-480.

Cargill, C. F., 1989, Information Technology Standardization -- Theory, Process and Organizations, Digital Press.

Davis, F. D., 1989, Perceived Usefulness, Perceived Ease of Use, and User Acceptance of Information Technology, MIS Quarterly 13 (3), pp. 319 -- 340.

Fleck, J., 1994, Learning by trying: the implementation of configurational technology, Research Policy, Vol. 23, pp. $637--652$.

Friedman, A., 1989, with Cornford, D. Computer Systems Development: History Organisation and Implementation, John Wiley \& Sons.

Gerrity, T. P., and Rockart, J. F., 1986, End-user computing: Are you a leader or a laggard, $\underline{\text { Sloan }}$ Management Review, Vol. 27 (4), pp. 25--34.

Hammer, M. and Champny, J., 1993, Re-engineering the Corporation, Nicholas Brearley, London.

Hawkins, R., Mansell, R., and Skea, J. Standards, Innovation and Competitiveness, Edward Elgar, 1994.

Jakobs, K. and Lenßen, K., 1994, Successful Applications of Electronic Messaging in International Organisations -- Strategies, Results, Experiences; European Electronic Messaging Association Report.

Jakobs, K., 1994 Electronic Messaging for Finance and Aviation -- Summaries of Two Case Studies, EEMA Briefing, Vol. 7 (4), pp. 16-17.

Jakobs, K. and Fichtner, M., 1995 Introducing Electronic Mail in Large Organisations -- Lessons Learned from Case Studies. Proceedings of the 1st International Conference on Telecommunications and Information Markets, pp. 137-143.

Jakobs, K., Procter, R. and Williams, R., 1996, Users and Standardisation -- Worlds Apart? The Example of Electronic Mail. To be published in ACM StandardView 4 (4).

Morris, C. R. and Ferguson, C. H., 1992, How Architecture Wins Technology Wars, $\underline{\text { Harvard Business }}$ Review, Vol. 71 (2), pp. 86-96.

Nelson, R. R. and Cheney, P.H., 1987, Training end users: An exploratory study, MIS Quarterly 11 (4), pp. 547-559. 
RACE Industrial Consortium (eds), 1995, Usability and Generic Applications, RACE Common Functional Specifications and Common Practice Recommendations, Document 14, Issue E.

Williams, R., 1994, Information Technology in Organisations, Report to European Commission DGIII Industrial Policy Directorate, IT Strategy Unit. Available as Edinburgh PICT Working Paper No 54.

Yaverbaum, G.J., 1988, Critical Factors in the User Environment: An Experimental Study of Users, Organizations and Tasks, MIS Quarterly 12 (1), pp. 75$-88$.
1 Author's present address:

Kai Jakobs, Technical University of Aachen,

Computer Science Department, Informatik IV, Ahornstr. 55, D-52056 Aachen, Germany, jakobs@informatik.rwth-aachen.de 